\title{
Gonorrhoea of the throat at a venereological clinic Incidence and results of treatment
}

\author{
LARS HALLQVIST AND SÖREN LINDGREN \\ From the Departments of Dermatology and Venereology, Central Hospital of Norrköping, \\ University of Linköping, Sweden
}

Occasional accounts of gonococcal infection of the throat have appeared in the literature since the 19th century, but no systematic investigations were published before the 1970s. Reports have now been made on the incidence, diagnostic criteria, paths of infection, symptomatology, complications, and treatment of the condition (Bro-Jørgensen and Jensen, 1973). We have studied certain aspects of gonorrhoea of the throat in two Swedish populations.

\section{Material and methods}

The series comprises 3,271 consecutive cases of gonorrhoea seen at the venereological clinics in two Swedish towns, Norrköping (2,179 cases) and Linköping (1,092 cases), during the years 1971 to 1974 .

In all cases swabs were taken from throat and urethra, and in women from the cervix and rectum also. Throat specimens were confined to the tonsils, and the same swab was used on both sides. In 24 patients with confirmed tonsillar gonorrhoea, samples of saliva were taken from the anterior part of the mouth before treatment. All specimens were taken with a cotton-wool swab and placed in Stuart's medium for transport to the laboratory.

Culture was carried out on blood agar plates with and without antibiotics ; in the case of tonsillar and rectal swabs antibiotics were always present in the media (Vancomycin ${ }^{8}+$ colistin + nalidixic acid). The colonies were examined by Gram staining, oxidase testing, and fermentation with glucose, laevulose, and maltose. The resistance to penicillin, ampicillin, and other agents was determined, a minimum inhibitory concentration (MIC) of $0.06 \mu \mathrm{g} . / \mathrm{ml}$. being set as the upper limit of full sensitivity for ampicillin.

The standard treatment for ano-genital gonorrhoea was a single dose of $2 \mathrm{~g}$. ampicillin $+1 \mathrm{~g}$. probenecid by mouth. When gonococci were demonstrated in the throat, treatment was carried out in accordance with one of the schemes shown in Table I.

After treatment the patient was re-examined and cultures were taken at least twice, at intervals of at least 1 week. In cases of tonsillar gonorrhoea, four cultures were taken after treatment, at intervals of 4 to 7 days.
TABLE I Regimens of treatment used in tonsillar gonorrhoea

A. Ampicillin 2 g. by mouth (single dose) + probenecid 1 g. by mouth B. Ampicillin $1 \mathrm{~g}$. four times a day for 3 days

C. $\mathbf{A}+\mathbf{B}$

D. Cephalexin $0.5 \mathrm{~g}$. four times a day for 5 days

E. Other prolonged treatment

1,886 consecutive patients were interviewed by a sociologist or doctor concerning oro-genital intercourse during the months preceding the examination.

\section{Results}

The incidence of tonsillar gonorrhoea is shown in Table II. Culture of saliva was positive in two patients with positive tonsillar cultures. Among the women were 108 who already had salpingitis and had already received treatment, usually with doxycycline.

TABLE II Incidence of tonsillar gonorrhoea among all patients with gonococcal infection

\begin{tabular}{lllll}
\hline Sex & Men & Women & Total \\
\cline { 1 - 1 } $\begin{array}{l}\text { All patients with } \\
\text { gonorrhoea }\end{array}$ & 1,723 & 1,548 & 3,271 \\
$\begin{array}{l}\text { Occurrence of } \\
\text { tonsillar } \\
\text { gonorrhoea in } \\
\text { above }\end{array}$ & 62 & $(3.6$ per cent. $)$ & $\begin{array}{l}90 \\
(5 \cdot 8 \text { per cent. })\end{array}$ & $\begin{array}{l}152 \\
(4 \cdot 6 \text { per cent. })\end{array}$ \\
$\begin{array}{l}\text { Tonsillar } \\
\text { gonorrhoea } \\
\text { alone }\end{array}$ & 17 & 19 & 36 \\
\hline
\end{tabular}

In the whole series 10 per cent. of strains showed diminished sensitivity to ampicillin ; among patients with tonsillar gonorrhoea diminished sensitivity was noted in 20 per cent., the resistance patterns being identical for organisms from both tonsils and genital tract.

Of the 1,886 patients with gonorrhoea who were questioned concerning oro-genital intercourse, 34 per cent. of men and 33 per cent. of women admitted oro-genital intercourse, whereas among patients with tonsillar gonorrhoea the figures were 76 and 86 per cent. respectively. Among patients admitting oro-genital intercourse, the incidence of tonsillar 
gonorrhoea was 7 per cent. in men and 16 per cent. in women, whereas the incidence of tonsillar gonorrhoea in the whole series was 3.6 per cent. in men and 5.8 per cent. in women.

Tonsillar cultures were positive on the first examination before treatment in 74 per cent. of the 152 cases of tonsillar gonorrhoea, on the second examination in 8 per cent., and not until the first to third examination after treatment of genital gonorrhoea in 18 per cent.

Two patients had gonococcal septicaemia and one had tonsillitis with marked pyrexia.

The results of treatment are shown in Table III. The numerals refer to the treatment sessions, and patients showing a recurrence of infection after treatment therefore appear in more than one treatment group.

No complications of treatment worthy of note were observed.

\section{Discussion}

In an unselected series of 3,271 patients with gonorrhoea, gonococci were isolated from the tonsils in 5.8 per cent. of women and 3.6 per cent. of heterosexual men. In previous reports corresponding figures of 10 to 11 per cent. and 5 to 7 per cent. have been given (Bro-Jørgensen and Jensen, 1973 ; Wiesner, Tronca, Bonin, Pedersen, and Holmes, 1973 ; Ödegaard and Gundersen, 1973). In the present series gonococci were isolated from the tonsils alone in 1 per cent. of all patients, a figure that agrees closely with the findings in similar investigations. The series includes 108 women suffering from gonococcal salpingitis who had been treated with antibiotics before the first throat swab was taken. This may have affected the figures for tonsillar gonorrhoea among the women in our series.

The lower incidence of tonsillar gonorrhoea in our series than in those referred to above may be due to differing sexual behaviour. Only 34 per cent. of our patients admitted oro-genital intercourse, compared to about 75 per cent. in the series of Bro-Jørgensen and Jensen (1973), but 81 per cent. of our patients with tonsillar gonorrhoea admitted oro-genital intercourse. These figures should probably not be regarded as reliable, for some of our patients who had at first denied oro-genital intercourse later admitted to this when the tonsillar cultures proved to be positive. Only two men (sexual partners) were recognized to be homosexual; both had ano-genital and tonsillar gonorrhoea.

Oro-genital intercourse, and in particular fellatio, is probably essential for the development of tonsillar gonorrhoea. Bro-Jørgensen and Jensen (1973) found positive tonsillar cultures in 38 per cent. of women with gonorrhoea who admitted oro-genital intercourse with the partner probably responsible for the infection. The importance of fellatio is also illustrated by the fact that, in homosexual men, among whom fellatio would appear to be practically the rule, the incidence of tonsillar infection has been said to be 13 to 25 per cent. of those with gonorrhoea (Bro-Jørgensen and Jensen, 1973 ; Owen and Hill, 1972 ; Wiesner and others, 1973).

The fact that some of our patients denied orogenital intercourse raises the possibility of autoinoculation by means of the fingers. The significance of 'deep kissing' has proved impossible to assess, but in two cases gonococci were demonstrated in the saliva in the anterior part of the oral cavity. The possibility of transmission of infection by kissing has recently been considered by Willmott (1974).

Because 18 per cent. of the cases of tonsillar gonorrhoea were discovered at the first, second, or third follow-up examination after the treatment of genital infection it was considered necessary to examine these patients four times after treatment.

We cannot explain why gonococci isolated from patients with tonsillar gonorrhoea show diminished sensitivity to ampicillin twice as often as those from patients with genital gonorrhoea. As far as we know, no similar observation has previously been reported.

TABLE III Results of 203 courses of treatment in 152 patients with tonsillar gonorrhoea

\begin{tabular}{|c|c|c|c|c|c|c|}
\hline \multirow[t]{2}{*}{ Treatment } & \multicolumn{2}{|c|}{$\begin{array}{l}\text { No. of courses } \\
\text { of treatment }\end{array}$} & \multicolumn{2}{|c|}{$\begin{array}{l}\text { Failure of } \\
\text { treatment }\end{array}$} & \multicolumn{2}{|c|}{$\begin{array}{l}\text { Failure ratel } \\
\text { follow-up }\end{array}$} \\
\hline & s & DS & $\mathbf{s}$ & DS & $\mathbf{S}$ & DS \\
\hline A. Ampicillin $2 \mathrm{~g}$. + probenecid $1 \mathrm{~g}$. & 59 & 23 & 28 & 14 & $28 / 56$ & $14 / 22$ \\
\hline B. Ampicillin 1 g. $\times 4$ for 3 days & 27 & 11 & 1 & 0 & $1 / 27$ & $0 / 11$ \\
\hline C. $\mathbf{A}+\mathbf{B}$ & 13 & 2 & 1 & 0 & $1 / 10$ & $0 / 2$ \\
\hline D. Cephalexin 0.5 g. $\times 4$ for 5 days & 33 & 12 & 1 & 1 & $1 / 29$ & $1 / 10$ \\
\hline E. Other prolonged treatment & 18 & & o & & $0 / 16$ & \\
\hline
\end{tabular}

( $\mathrm{S}=$ sensitive to penicillin/ampicillin. DS = diminished sensitivity). 
TABLE IV Results of single-dose therapy of tonsillar gonorrhoea compared with previous investigations

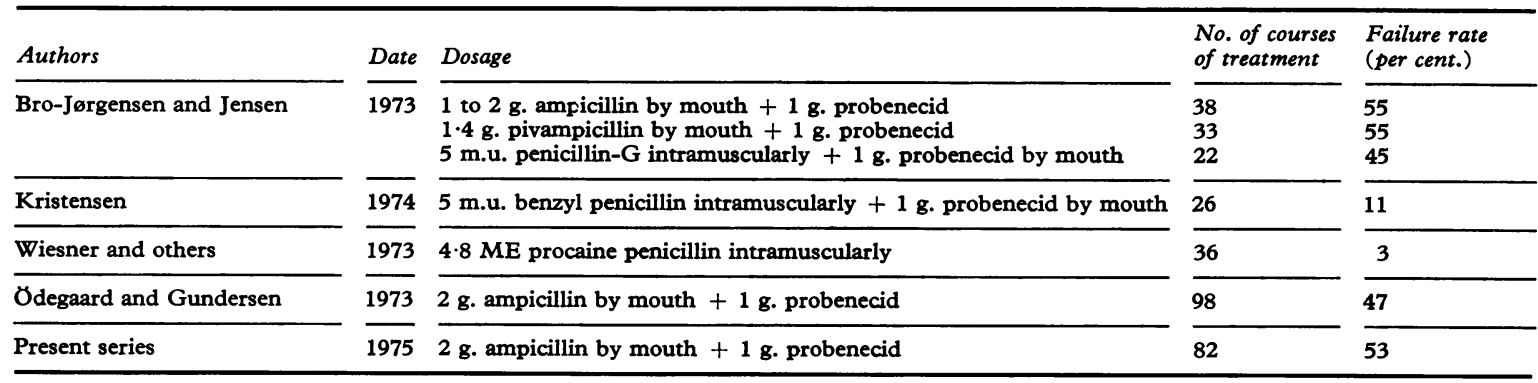

The results of the standard treatment with $2 \mathrm{~g}$. ampicillin $+1 \mathrm{~g}$. probenecid in a single oral dose are unsatisfactory in tonsillar gonorrhoea, the failure rate being 54 per cent. In this connection the ampicillin sensitivity of the organisms is apparently irrelevant. Other clinicians have reported equally poor results with single-dose therapy (see Table IV). In the treament of genital gonorrhoea by the same method, on the other hand, the recurrence rate was only 2 per cent.

Kristensen (1974) reported recurrence in three of 26 cases after parenteral single-dose treatment of tonsillar gonorrhoea with 5 m.u. benzyl penicillin + 1 g. probenecid, and Wiesner and others (1973) found recurrence in one of 36 cases after parenteral single-dose treatment with $4.8 \mathrm{~m}$.u. procaine penicillin. These results are better than those with single-dose oral treatment.

Oral treatment is preferable because of the lower risk of serious complications and because it does not discourage patients from attending and also makes less work for the nursing staff. We obtained satisfactory results with either ampicillin $1 \mathrm{~g}$. four times a day for 3 days or cephalexin $0.5 \mathrm{~g}$. four times a day for 5 days. From and Veien (1974) reported a series of thirteen patients with tonsillar gonorrhoea all of whom recovered after 5 days' treatment with pivampicillin $1.4 \mathrm{~g}$. + probenecid $1 \mathrm{~g}$. once daily in a single dose. However, owing to the risk of allergic complications associated with prolonged penicillinprobenecid treatment (Ström, 1957), the use of ampicillin requires a shorter but more intensive treatment period.

Treatment was always given as soon as tonsillar gonorrhoea was diagnosed. We found that treatment with ampicillin $1 \mathrm{~g}$. four times a day for 3 days or cephalexin $0.5 \mathrm{~g}$. four times a day for 5 days was equally effective. The complication rate was low, but Wiesner and others (1973) reported a raised complication rate in tonsillar gonorrhoea.

\section{Summary}

Among 3,271 consecutive cases of gonorrhoea seen during the years 1971 to 1974 , the incidence of tonsillar gonorrhoea was 3.6 per cent. in men and 5.8 per cent. in women. Oro-genital intercourse was admitted by 34 per cent. of men and 33 per cent. of women. Among these patients the incidence of tonsillar gonorrhoea was 7 per cent. in men and 16 per cent. in women. Only two cases of gonococcal septicaemia were seen, and there were no other complications. Few patients experienced symptoms from the throat. Tonsillar culture was positive on the first examination in only $\mathbf{7 4}$ per cent., it was negative until after single-dose treatment had been given in 18 per cent.

Single-dose treatment with $2 \mathrm{~g}$. ampicillin $+1 \mathrm{~g}$. probenecid by mouth was unsatisfactory, with a 54 per cent. failure rate in cases of tonsillar infection. Treatment with ampicillin $1 \mathrm{~g}$. four times a day for 3 days failed in only one out of 35 cases and Cephalexin $0.5 \mathrm{~g}$. four times a day for 5 days failed in two out of 39 patients. No side-effects of treatment were seen. It is concluded that these two treatment schedules can be used with equally satisfactory results in patients with tonsillar gonorrhoea.

\section{References}

Bro-Jørgensen, A., and Jensen, T. (1973) Brit. f. vener. Dis., 49, 491

From, E., and VeIen, N. K. (1974) Ibid., 50, 360

KRISTENSEN, J. K. (1974) Ugeskr. Laeg., 136, 753

ÖDEGAARD, K., and GUNDERSEN, T. (1973) Brit. F. vener. Dis., 49, 350

Owen, R. L., and Hill, J. L. (1972) f. Amer. med. Ass., 220, 1315

STRöm, J. (1957) Acta paediat. scand., 46, 387

WIEsNer, P. J., Tronca, E., Bonin, P., Pedersen, A. H. B., and Holmes, K. K. (1973) New Engl. $\mathcal{F}$. Med., 288, 181

WILlMotT, F. E. (1974) Brit. F. vener. Dis., 50, 317 